\title{
UC leads effort to protect California forests from catastrophic fire
}

$\mathrm{F}$ ire has always been a part of California's Sierra Nevada ecosystem, but over the past 100 years, a national fire suppression policy has disrupted the natural order.

"By studying fire scars on tree rings, scientists have confirmed that before fire suppression, the Sierra Nevada's mixed conifer forests burned every 15 to 35 years. The forests were more open and didn't have as much ground fuel," said Susie Kocher, UC Cooperative Extension advisor in the Central Sierra, a forestry expert. "Today's overstocked forests are primed for catastrophic fire."

In 2005, the U.S. Forest Service, UC and other state and federal agencies signed a

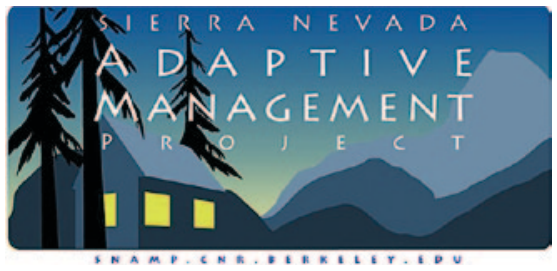
memorandum of understanding to create the Sierra Nevada Adaptive Management Project (SNAMP). SNAMP researchers are studying forest management and documenting modern, sustainable techniques that will return forest environments to a more natural density. A unique funding partnership - involving the California Department of Water Resources, the Forest Service, private foundations and other sources - provided about \$15 million.

"Climate change is giving us an even longer and drier fire season," Kocher said. "Adapting forest management to make Sierra Nevada forests more fire resilient is an urgent task."

\section{Humans and forest fire}

Human impacts on the forests of California's Sierra Nevada can be almost imperceptible in the short run, but profound over time. The consequences of forest management decisions made 100 years ago are still felt today, and changes in management being made now will shape the forest, wildlife, watersheds and nearby communities long into the future.

For eons, intermittent fires regularly pruned low shrubs, killed small trees and converted forest duff to ash. Low-intensity burning was also part of Native American culture. But through most of the 20th century, natural forest fires were quickly suppressed. The new, fire-suppressed landscape, rife with vegetation, can fuel less frequent but all-enveloping infernos that destroy whole communities in their paths.
USDA research found that fire size and the area burned in the western United States has risen substantially since the early 1980s and are now at or above values from before the 1940s, when fire suppression became national policy. Also, a large area of California and western Nevada experienced an increase in highseverity fire between 1984 and 2006.

\section{Forest Service partners with UC}

The U.S. Forest Service is responsible for more than 20 million acres in California, including striking vistas, rich wildlife habitat and invaluable watersheds, much of it adjacent to rural communities. The agency was charged by Congress with managing the nation's forests for multiple uses - water, forage, wildlife, wood and recreation. However, historical missteps eroded the agency's credibility among some forest community residents and people dedicated to protecting Sierra wildlands and wildlife. Management projects were contested in court at every turn, to the point that fire hazard management, especially if it involved removing large trees, was essentially at a standstill.

In the mid-2000s, the Forest Service, along with state partners, turned to UC to document the effects of an integrated, science-based, vegetation management strategy that would modify landscape-scale fire behavior to reduce the size and severity of wildfires. UC was asked to serve as a neutral third party, to research key management issues and increase public participation in all aspects of fuel management strategy.

"UC was chosen because of its

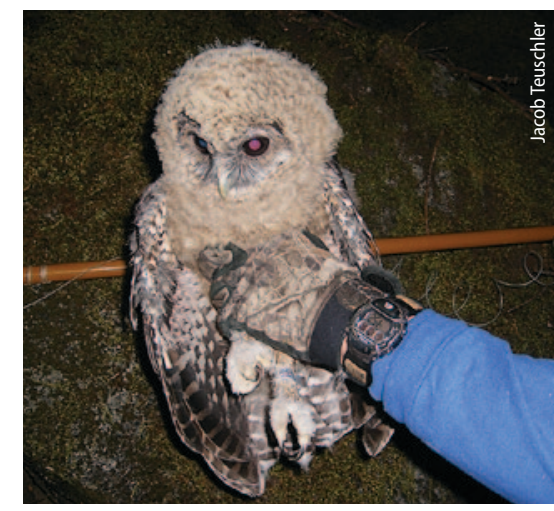

About 75 California spotted owls have been banded in the Last Chance study area. credibility on all sides of Sierra forest management debates," said Richard B. Standiford, who as associate vice president for UC Agriculture and Natural Resources negotiated UC's involvement in SNAMP; he is now UC Berkeley Cooperative Extension specialist, a forest management expert. "We wanted to try a completely new approach, to integrate science and public participation from the start so forest management plans could move forward."

Adaptive management is a learn-bydoing approach, which allows managers to take action without complete information about a system. For SNAMP that meant scientists would collect and analyze pretreatment data, then the Forest Service would choose and carry out forest fuels treatments, including tree and brush removal and prescribed burns. During and after the treatments, scientists conduct research and report the results back to the Forest Service and the public to improve future fuels reduction treatments. 
"In a scientifically sound adaptive management program, management is done as part of experimental treatments," said UC Berkeley environmental sciences professor John Battles, principal investigator for the multiteam project. "In SNAMP, we have tried to stay true to this vision while having scientists interact directly with stakeholders about all aspects of the scientific approach."

\section{Reducing fire danger}

The Forest Service's goal is to diminish fire danger on $100 \%$ of an area by reducing trees and brush on about $20 \%$ to $30 \%$ of the landscape. This strategy is based on the theory that disconnecting areas with fuel concentrations will reduce the intensity of fire and so increase the percentage of trees and vegetation that survive. Two sites in the western Sierra Nevada were selected for the study: the Sugar Pine Project in the Sierra National Forest south of Yosemite National Park and the Last Chance Project in the Tahoe National Forest.

"Our project sites represent the major bio-geographical features of the Sierra Nevada," Battles said. "These mixed conifer forests offer suitable control and treatment watersheds and mature forest habitat for the wildlife species we wanted to study. They are also large enough to support landscape-scale research and planning by local Forest Service rangers."

In 2011, the Forest Service implemented three fuel reduction treatments in strategically placed areas of the Last Chance Project, including mechanical thinning and prescribed fire, as well as some treatments in the Sugar Pine Project. All treatments in both areas should be completed in 2012.

SNAMP includes six research and outreach teams, with 12 principal investigators and representatives from UC Berkeley, UC Merced, UC Cooperative Extension and the University of Minnesota. Each team has made progress toward their goals:

Fire and forest health. The fire and forest health team is investigating the effects of strategic fuel treatments on fire behavior and tree and forest health, and documenting fire histories for the two study areas. The team has collected data on tree size and species, analyzed hundreds of tree core samples and compared growth patterns of live and dead trees. They predict that the Forest Service treatments, when completed, will be effective at moderating wildfire behavior. Initial evidence suggests that forest thinning for fire control will improve tree growth even under adverse environmental conditions, such as drought.

California spotted owl. This team is surveying the Last Chance study site and nearby areas for owls and monitoring their breeding status. California spotted owls select habitats that have large trees and high canopy cover. The team has identified 75 owls in 48 territories within the study area. Using monitoring data, initial findings suggest that the owl population is in overall decline. The team is conducting

\section{For more information:}

Sierra Nevada

Adaptive Management Project http://snamp.cnr.berkeley.edu

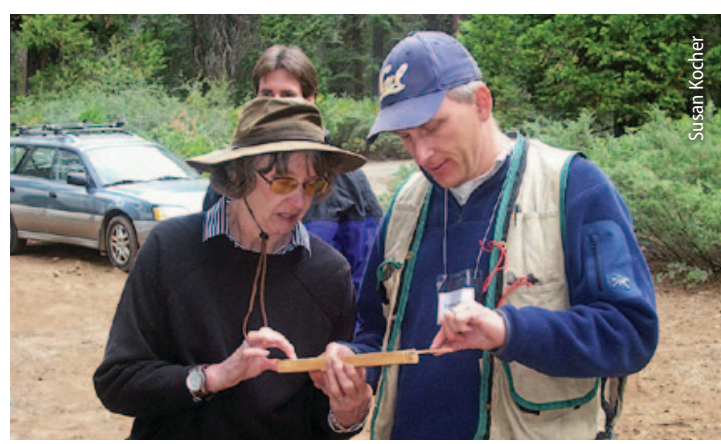

UC Berkeley forest ecologist John Battles shows a SNAMP workshop participant how to read a tree ring core, near Forestville. team uses strategic facilitation and outreach to support the progress of adaptive management in the two project areas. The team hosts meetings, field trips, lectures, annual conferences and public presentations. It reaches a large and diverse population with submissions to blogs, industry publications and traditional media outlets, and maintains the SNAMP website. The team also researches how various public participation initiatives contribute to the adaptive management process and decision-making about Sierra Nevada forests. The team is hosting a public meeting on June 22 in Sacramento to develop recommendations and receive input on concluding the project in 2014. 